\title{
As sedutoras da camiseta: mito, conflito e imaginário em jogo
}

\section{Euler David de Siqueira e Denise da Costa Oliveira Siqueira}

\section{Resumo}

0 objetivo deste artigo é investigar a produção de sentidos sobre o corpo feminino a partir de um imaginário de gênero posto em evidência por meios de comunicação. Partindo de um referencial teórico que inclui Durand, Wunenberger e Le Breton, fazemos uma leitura da polêmica desencadeada pelo lançamento de produtos referentes à Copa do Mundo realizada no Brasil contendo imagens de caráter ambíguo sobre a mulher brasileira. A questão teve destaque na imprensa internacional, instaurando um campo polifônico e polissêmico repleto de tensão. Metodologicamente, esta é uma pesquisa de natureza qualitativa orientada pelos princípios da sociologia compreensiva. Por meio de pesquisa documental de material midiático, assim como da leitura das falas, relacionamos mitos, imaginários e conflitos, tendo em vista sua oposição e complementaridade. Finalmente, fazendo uso da distinção entre problema social e problema sociológico, buscamos compreender a situação em termos de interação social.

\section{Palavras-Chave}

Corpo. Imaginário. Gênero. Conflito. Interação.

Euler David de Siqueira I euleroiler@gmail.com Doutor em Sociologia pela UFRJ, Brasil. Pós-doutor em Sociologia pela Sorbonne/Université Paris-Descartes, França. Professor da UFRRJ, Brasil. Pesquisador do Programa de Pós-Graduação em Ciências Sociais da UFJF, Brasil.

\section{Denise da Costa Oliveira Siqueira ।}

denise.siqueira@yahoo.com.br

Doutora em Ciências da Comunicação pela USP, Brasil. Pósdoutora em Sociologia pela Sorbonne/Université Paris-Descartes, França. Professora do Programa de Pós-Graduação em Comunicação da UERJ, Brasil.

\section{Introdução}

0 sentido veiculado pela imagem jamais é pleno. A frase, tomada emprestada do pensamento de Gilbert Durand (2003), é significativa do trabalho que buscamos empreender neste artigo: investigar a produção de sentidos sobre 0 corpo feminino a partir de um imaginário de gênero posto em evidência por meios de comunicação.

Em uma época em que a imagem adquire um estatuto quase absoluto - Durand fala de inflação da imagem e de uma zona de alta pressão imaginária ,- 0 corpo não deixa esquecer que estamos material e simbolicamente associados a ele. Desde o texto seminal de Marcel Mauss (1985) sobre as técnicas corporais - que faz par com a noção de fato social total-, o corpo adquiriu importância a ponto de não ser mais possível ignorá-lo: está em todos os lugares, materializado, representado, imaginado e configura-se como espaço para estudo da sociedade, da cultura, do imaginário.

\section{A consciência do lugar central do corpo se} reflete em um imaginário corporal que articula 
natureza e cultura e que participa do processo em curso de remitologização do mundo (DURAND, 1996). Como sintetizou Wunenburger, "o corpo certamente designa, em primeiro lugar, uma realidade objetiva e biológica dotada de órgãos, funções, fronteiras e superfícies, mas a nossa relação pessoal, subjetiva e íntima com 0 corpo se desenvolve também por meio de um conjunto de representações que 0 modificam, sobrecarregam-no de valores negativos ou positivos, transformam seu estado natural ou suas aparências sensíveis" (2006, p.193).

0 pensamento de Durand (2003) possibilita um importante suporte para refletir sobre o corpo, suas posturas, seus gestos e movimentos como organizadores de imagens. De fato, entre o sujeito e 0 mundo exterior encontra-se 0 corpo, interface mediadora que tanto modifica 0 ambiente no qual se encontra inserido como também por ele é alterado, nota Christine Detrez, em $L a$ construction sociale du corps (2002).

Partindo dessas pistas, nossa investigação toma como ponto de partida um objeto carregado de concretude para nos remeter a uma aparição. Esse objeto são imagens visuais de corpos femininos estampadas em camisetas nos Estados Unidos pela empresa Adidas para a Copa do Mundo de 2014 e cujo sentido, ambíguo, acionou discursos de importantes atores sociais contra uma possível exploração da mulher brasileira. Em termos de problema de pesquisa, estamos em um carrefour em que representações do corpo feminino articuladas a um esporte predominante masculino comunicam mensagens sobre uma suposta sensualidade feminina naturalizada e mitificada nos trópicos.

Buscamos avançar pistas deixadas por Durand a fim de refletir sobre o museu de imagens que domina o campo midiático contemporâneo. Na esteira desse pensamento, 0 antropólogo francês David Le Breton assinala que "a imagem torna-se mundo" (2005, p.203). É assim que olhamos o conflito estudado na perspectiva de seu caráter simbólico, mítico e que encontra no corpo e em suas imagens o reflexo do imaginário. A problemática das camisetas da Copa remete ao campo abstrato da moral, campo de predileção da imagem simbólica.

Nessa perspectiva, a problemática das camisetas ultrapassa a realização temporal do evento esportivo de 2014 ao qual faria referência, tamanha a carga emocional e simbólica investida, e merece ser retomada e discutida em uma perspectiva dos estudos do imaginário. Trata-se de algo que aciona, mais uma vez, um campo atravessado de tensão e ambiguidade em que imagens e imaginários tornam-se peças importantes de um jogo no qual os atores sociais trocam acusações recíprocas. Como Durand frisa, o mito em si mesmo não é nem bom nem mal: tudo depende do uso que dele é feito pelos sujeitos com consequências, às vezes, perigosas. 
Metodologicamente, esta pesquisa caracteriza-se como sendo de natureza qualitativa e orientada por pressupostos da sociologia e da antropologia compreensivas para a leitura de um material do campo da comunicação. Por meio de pesquisa bibliográfica e documental, assim como de leitura de enunciados em matérias jornalísticas, nosso objetivo é mapear 0 imaginário em representações coletivas expressas nesse incidente repleto de possibilidades.

Ao tangenciar um tema sensível - a imagem da mulher brasileira em produtos midiáticos -, nossa pesquisa também busca discutir a relação entre problema social e problema sociológico. 0 problema social, identificado como tal por grupos ou organizações oficiais, não deve ser visto como verdade, mas como uma perspectiva cuja missão do analista social é ultrapassar para não incorrer em tomar como totalidade apenas uma parte de um sistema mais vasto de interpretações sociais (BERGER, 1980).

\section{Corpo e imaginário: 0 contexto}

Imagens do corpo feminino representadas em produtos, em obras de arte ou religiosas - só para pensar em algumas possibilidades - remetem ao campo do simbólico. 0 sentido simbólico, que dificilmente se revela, afinal, nas palavras de Durand, constitui o mistério de uma epifania (2003), encontra no corpo um poderoso organizador de imagens.
Ao refletir sobre o corpo e a modernidade, notadamente no campo da imagerie médica, David Le Breton relativiza a hegemonia do signo frente ao símbolo, supostamente ultrapassado pelo primeiro: "Toda imagem, mesmo a mais asseptizada, a mais rigorosamente sujeitada pelo signo, suscita no homem um apelo ao imaginário. (...) Mesmo isolada de toda imagem de fundo, despojada de sua espessura, reduzida a pura informação, a imagem favorece a deriva, incita 0 desvio" (2005, p.217).

Wunenburger nota que o imaginário não se restringe ao campo do que é percebido, mas também integra 0 coletivo e 0 individual: " 0 imaginário de um indivíduo ou de um grupo se desenvolve, portanto, como uma formação de representações e de crenças em realidades que excedem o plano da experiência sensorial e que formam um mundo próprio, que pode nutrir narrativas (mitos sociais) e comportamentos de atualização ou de manipulação sob forma de ritos" (2013, p.17).

Em sua análise sobre a importância do corpo no processo de comunicação e de agenciamento do imaginário, Christine Detrez aponta que "a publicidade e 0 cinema fornecem a esse respeito um corpus infinito de ilustração desses códigos" (2002, p.150). A autora nota, ainda, que 0 agenciamento de representações do corpo feminino é revelador de interesses de grupos particulares da sociedade. Desse modo, a discussão sobre 0 imaginário não deve 
negligenciar o fato de que relações de poder e de dominação também condicionam as disputas em jogo. Para Detrez, a publicidade desempenha um papel importante na mediação entre dominação e vestimenta: "0 imaginário do corpo liberado, paradoxalmente, pode ser interpretado como uma nova forma particularmente eficaz - tanto mais eficaz que ela é menos explícita e se esconde em seu contrário - da dominação social, que nós vimos que é constitutiva de relações sociais ao corpo" (2002, p.206).

As polêmicas desencadeadas pela forma como 0 corpo feminino é interpretado e usado não são um fato recente. Desde a chegada do explorador europeu ao litoral da América do Sul, os corpos de homens e mulheres bronzeados e bem nutridos, vivendo em "estado de natureza", fazem paralelo com mitos de origem religiosa como o do Paraíso ou do Jardim do Éden que circulavam bem antes da Idade Média pela Europa.

Em trabalhos anteriores, discutimos as relações entre 0 corpo feminino, os cartões-postais e o imaginário sobre a cidade do Rio de Janeiro (SIQUEIRA, SIQUEIRA, 2011). Postais com imagens de jovens mulheres bronzeadas de biquíni nas praias da Zona Sul do Rio eram vendidos livremente até a metade dos anos 2000 sem que se enxergasse nisso algo de errado. Em 2005, uma lei proibiu a comercialização, a divulgação e a circulação de imagens de mulheres fora de seu contexto natural. 0 apito havia sido trilado por um empresário moral
(BECKER, 1978) e, desde então, nunca mais uma nádega exibida em um postal seria vista apenas como mais uma nádega: aquelas fotos agora eram vistas como incitadoras de um imaginário de forte caráter sexual e, portanto, de um comportamento desviante.

0 antropólogo canadense Franck Michel também chamou a atenção para a proibição de postais que exibiam jovens de biquíni nas praias cariocas:

Todo mundo sabe (como se diz) que a imagem do Rio de Janeiro não é somente o Cristo na Cruz ou a praia de Copacabana, mas, sobretudo, a jovem local, mulata de preferência, lasciva, de biquíni. A cidade decidiu, contudo, interditar a venda de cartões-postais mostrando brasileiras assim desnudadas - imagem turística do Rio a fim de não degradar a reputação da "cidade maravilhosa" e, mais ainda, segundo as autoridades, de lutar contra o crescimento inquietante do turismo sexual na região. (2011, p.96).

0 caso dos "postais proibidos", como os chamamos à época, faz lembrar que nos anos 1960, 1970 e 1980 as campanhas da Embratur associavam imagens de mulheres ao turismo no Brasil. A mulher seria um complemento às belezas naturais do país. Essa abordagem, no entanto, explica apenas uma parte do mito da sensualidade da mulher brasileira e do Brasil como paraíso sexual. Com a mudança de estratégia do governo, desde os anos 2000, os corpos femininos desapareceram da propaganda turística oficial.

Em sua obra Sur la plage: moeurs et coutumes balnéaires, o sociólogo francês Jean Didier Urbain 
ressalta que o corpo presente nas praias é, acima de tudo, um corpo construído. Segundo o autor, esse corpo "é um signo específico. Sua nudez, nós a vimos, não é um defeito do código. Ela é, ao contrário, um fato de linguagem. É uma mensagem complexa" (1994, p.316).

Urbain destaca que o corpo está longe de representar esse dado natural evidente ao observador. 0 corpo é cultura; se faz cultura; ele é sociedade, aqui entendida como forma de interação; é a sociedade encarnada, inscrita na carne com todas as suas contradições e ambivalências. Nos discursos turístico e esportivo atuais, o corpo feminino de biquíni é algo a ser evitado sob pena de desencadear acusações e suscitar debates acalorados para os quais o sistema não possui uma resposta clara e inequívoca. Problema social para uns, o corpo seminu ou nu na praia é também um problema sociológico: constrói mensagens, estabelece 0 diálogo, explicita concepções de mundo. É nesse sentido que o corpo na praia se reveste de um sentido comunicante: para Urbain, o corpo é metáfora.

A questão que foi alvo de empresários morais ganha novas interpretações quando observada por outro ponto de vista, isto é, como interação social. A mesma imagem de parte do corpo feminino no postal ou na camiseta que incomoda o governo e os ativistas pode figurar em uma capa de jornal sem que uma atenção especial lhe seja dirigida. Jornais cariocas com forte apelo popular como
Extra e Meia-Hora exibem recorrentemente fotos de mulheres de biquíni em suas capas, sem que sejam acusados de incitar o turismo sexual ou atentar contra a integridade da mulher. Com as redes de computadores interligados em linha, cai por terra a ideia de que imagens como essas não teriam repercussão em outras partes do globo.

Assim, uma imagem de parte de um corpo feminino brasileiro - as nádegas - em um jornal estrangeiro exalta os ânimos e desencadeia duras reações, nisso que reconhecemos ser claramente um problema social. Antes da Copa, em novembro de 2013, o jornal croata 24 Sata veiculou em sua capa a imagem das nádegas de uma atleta brasileira com uniforme depois que sua seleção de futebol foi classificada para a competição que aconteceria no Brasil. A repercussão foi imediata, sendo alvo de reprovação e de crítica sobre como a mulher brasileira é retratada no exterior.

\section{0 sociólogo francês Michel Bozon avança pistas} interessantes à construção do imaginário sexual que se instaurou entre Norte e Sul. Em Sociologie de la sexualité (2005), o autor mostra que 0 imaginário ocidental foi ampliado consideravelmente quando europeus chegaram ao Novo Mundo em fins do século XV. Viagens de homens, principalmente, elas se distinguiam das viagens de colonização, assinala 0 autor. Para Bozon (2005), os primeiros exploradores representavam os nativos como seres ingênuos ou pervertidos. Em muitos casos, a facilidade com que as mulheres ofereciam-se ao viajante escondia uma intrincada rede de relações, 
como a busca de uma aliança, algo ainda mal compreendido pelo explorador.

0 imaginário a respeito de uma suposta "sensualidade natural" das mulheres brasileiras é, portanto, mais antigo do que pressupomos. Como sublinha Bozon: "0 mito da sexualidade dos mares do sul se prolongou até a época contemporânea ${ }^{1 "}$ (2005, p.85). Estamos, para todos os efeitos, diante de uma estrutura mítica da qual as imagens presentes nas camisetas são mais uma versão. Como explica Claude Lévi-Strauss (1991), estruturalmente, o mito não possui fronteiras: propaga-se aqui; é reinventado ali; ressignificado acolá; sempre diferente, ainda que mantendo uma mesma forma.

A mobilidade de massa contemporânea é um fenômeno que institui novas dinâmicas às trocas nada assimétricas entre visitantes e visitados.

Nas palavras de Bozon, "Com o turismo internacional, as viagens de grande escala se multiplicaram, fazendo surgir novos tipos de contatos diretos, nos quais a possibilidade de relações sexuais entre indivíduos do norte e do sul é apresentada" ${ }^{2 \prime}(2005$, p.89).

Ainda de acordo com Bozon, é preciso situar as trocas sexuais em um quadro histórico e social capaz de torná-las coerentes. Em outras palavras, temos situações de isolamento, como é o caso de resorts do tipo all inclusive, em que turistas viajam a outros países sem, necessariamente, manter qualquer contato com a população local, afinal, "Viagens e turismo não implicam necessariamente um contato entre culturas" (BOZON, 2005, p.88).

Em outros contextos, turistas europeus de classe média viajam dentro de um quadro de referências e valores que incluem a busca do amor romântico, 0 amor venal e até mesmo 0 casamento. A prostituição não seria, então, a única forma de relação sexual entre turistas e habitantes locais. Enquanto a prostituição implica um tipo de relacionamento efêmero, outras formas de relações sexuais carregam aspirações, como a de conseguir um casamento com um europeu fiel, romântico, compreensivo, bom pai de família e não machista.

Na perspectiva da interação social, os homens europeus veem as brasileiras como sensuais, quentes e submissas, enquanto rotulam negativamente as mulheres europeias como frias, reservadas e independentes. Ao mesmo tempo em que valorizam os homens europeus, as brasileiras representam negativamente 0 brasileiro considerado violento e que pensaria somente em sexo (BOZON, 2005, p.89).

Le mythe de la sexualité des mers du sud s'est prolongé jusqu'à l'époque contemporaine ». (2005, p.85).

«Avec le tourisme international, les voyages à la grande échelle se sont multipliées, faisant apparaître de nouveaux types de contacts directes, dans lesquels la possibilité de relations sexuelles entre individus du nord et du sud est présente ». (BOZON, 2005, p.89). 
Absoluto na mídia nacional, o corpo da brasileira habita também um certo imaginário global, pelo menos é isso que podemos depreender de um anúncio publicitário veiculado na revista Elle francesa, em 1992, citado por Urbain em sua obra:

Nádegas de sonho? Eis o ponto sensível! Você que deseja aquelas das brasileiras, as mais belas bundas do mundo, tão femininas e com 0 tônus muscular inegável, não passe mais seu verão a se lamentar em vão. Hoje, a pesquisa médica propõe uma pequena maravilha tecnológica: uma novidade incontestável ${ }^{3}$ (URBAIN, 1994, p.318).

0 anúncio mostra um derrière moreno, com maillot prateado que deixa as nádegas à mostra. Ao fundo, um mar azul. Nada na foto da revista francesa garante que o derrière retratado seja brasileiro - só a fama. 0 rosto da modelo não aparece, ela não pode ser identificada.

A atual reação enérgica do governo brasileiro, bem como de agentes privados do turismo, tanto no caso dos postais quanto no das camisetas, sublinha o corpo feminino como assunto delicado a ser tratado e retratado com atenção. Mostra que a representação explicitada no anúncio francês da década de 1990 não é mais considerada favorável para o Brasil. Hoje, aquele texto não seria mais elogioso.

\section{A brasileira nas camisetas: definição do problema social e o papel da mídia}

0 imaginário não se coloca à parte da sociedade, antes, participa dela ativamente. Assim é que lemos as imagens e os fatos que aconteceram a poucos meses do início da Copa do Mundo de futebol no Brasil, quando a empresa multinacional Adidas lançou, em seu site norte-americano, duas camisetas referentes ao evento. As $t$-shits eram ilustradas com imagens que logo foram consideradas ofensivas à mulher brasileira e tornaram-se alvo de intensa reação por parte de autoridades brasileiras, incluindo a então presidente do Brasil, Dilma Rousseff, que para tal usou sua conta na rede social Twitter.

A rápida reação ao lançamento da marca foi ainda mais enfática, tendo em vista 0 investimento sistemático que 0 governo brasileiro tem feito em políticas visando a desvincular o Brasil do roteiro do turismo sexual internacional. A despeito desse investimento, a persistência do tema assinala que 0 país ainda está longe de se desvencilhar da imagem de um lugar onde 0 sexo farto e fácil, junto com o samba, o futebol e o Carnaval encontram eco em um imaginário construído por séculos de "olhar estrangeiro".

«Des fesses de revê? Le voilà le point sensible! Vous qui enviez celles des Brésiliennes, les plus belles fesses du monde, si fermes et au tonus musculaire inégalabe, ne passez plus votre été à vous lamenter en vain. Aujourd'hui, la Recherche Médicale vous propose une petite merveille technologique : une Nouveauté Incontestable ». (URBAIN, 1994, p.318).

Parafraseando o documentário Olhar estrangeiro, de Lucia Murat, Brasil, 2006. Filme sobre os clichês e as fantasias sobre 0 Brasil no cinema internacional. Baseado no livro 0 Brasil dos gringos, de Tunico Amâncio. 
Na verdade, estamos longe de um consenso em torno do conflito que se instaurou entre, de um lado, o Governo brasileiro e, de outro, uma renomada empresa do mundo do esporte. Além da reação indignada de muitos contra 0 uso considerado indigno do corpo da mulher brasileira, não faltaram aqueles que se mostraram indiferentes, enquanto outros, em uma forte posição etnocêntrica negativa, atribuíram 0 incidente à falta de respeito e vergonha dos próprios "brasileiros".

Afinal, o que foi veiculado nas camisetas apontadas pelo governo e por parte da mídia como ofensivas? Na primeira camiseta, de cor verde, havia a frase em inglês "I Love Brasil" tendo sido o verbo to love substituído por um coração estilizado em formato de nádegas de biquíni. A segunda camiseta, na cor amarela, exibia a imagem de uma jovem de biquíni ao lado de um ícone do turismo carioca, o morro do Pão de Açúcar, com a seguinte frase: 'Lookin' to Score". A frase, dotada de um sentido malicioso, deixa entrever certa conotação sexual, pois significaria fazer pontos no esporte e na conquista de mulheres.

0 caso das camisetas da Copa teve ampla repercussão. Jornais brasileiros de circulação nacional, como $O$ Globo, além do francês $L e$ Monde, da revista esportiva francesa L'Equipe, a rádio France Info e o jornal inglês The Guardian deram destaque em seus noticiários ao "incidente". A rádio France Info e a revista
L'Equipe também exibiram comentários de seus leitores.

A enérgica reação do governo brasileiro à divulgação e venda das camisetas - julgadas ofensivas, incitadoras do turismo sexual e mesmo de pedofilia - deixou claro que as autoridades não tolerariam nenhum tipo de publicidade que fizesse alusão ao universo nada claro da sensualidade brasileira. A empresa rapidamente retirou de venda as camisetas e formulou uma mensagem pública - o que é revelador das implicações políticas e econômicas do conflito.

A acusação do governo brasileiro também repercutiu nas redes sociais, notadamente no Facebook, onde as reações foram virulentas, rápidas e enérgicas contra a marca alemã. 0 que talvez pretendesse ser uma divertida estratégia de marketing destinada a celebrar um dos maiores eventos esportivos do mundo ganhou dimensões não previstas com as redes sociais, instaurando um campo de tensão.

0 incidente das camisetas nos coloca no campo dos valores e da forma como a mídia abordou 0 assunto. 0 que, para muitos envolvidos, constituiu um problema social a ser atacado e combatido - a veiculação de imagens sensuais do corpo feminino e que hoje remetem a turismo sexual - para o cientista social, se mostra como um problema sociológico. Entre eles, há uma enorme diferença. 0 turismo sexual, esse inimigo invisível que assola a imagem do Brasil há décadas ou 
mesmo séculos, é um problema social segundo as definições oficiais dadas por organizações, como o governo. Entendemos que a tarefa do cientista social consiste em ir além das definições oficiais daqueles que consideram que algo na sociedade "não funciona como deveria funcionar". Portanto, nosso objetivo é o de compreender o incidente das camisetas em termos de interação social sem perder de vista 0 sentido ambíguo presente nas imagens das camisetas (BERGER, 1980).

Ao noticiar que as imagens nas camisetas fariam alguma alusão ao sexo e ao turismo sexual, a mídia definiu o problema como social. Dito de outro modo, ela reproduz a maneira como um grupo define a realidade social em termos de seus próprios valores e normas. Isso significa dizer que a mídia explicita seus valores e interesses de forma interessada e parcial. A análise de algumas matérias em que as camisetas são 0 centro do debate talvez deixe isso mais claro.

Em matéria publicada no caderno Esportes de $O$ $G l o b o^{5}$, do dia 24 de fevereiro de 2014, o jornal carioca noticiava que camisetas alusivas à Copa do Mundo no Brasil com apelo sexual eram vendidas em um shopping em San Francisco. A reportagem informava ainda que a coleção fazia referência às mulheres brasileiras. Após a descrição das imagens das camisetas, um vendedor foi questionado pelo jornalista se acreditava que as imagens nas camisetas incitavam o turismo sexual. A resposta foi a de que ele não havia reparado no conteúdo da imagem. 0 fato apresenta imediatamente uma questão: quem vê na representação do corpo feminino um problema social? Para 0 vendedor, a referência às nádegas e ao corpo não necessariamente indicou que algo estaria "errado".

Depois de colher o depoimento do vendedor, que parecia não se importar com a situação, a matéria dava destaque à reação das autoridades brasileiras. Esse recurso é recorrente e busca saber o que será feito "pelas autoridades" para solucionar 0 caso. A primeira autoridade a ser ouvida pelo $O$ Globo foi 0 presidente da Embratur, Flávio Dino, que disse:

Não aceitaremos que a Copa seja usada para práticas ilegais, como o chamado turismo sexual. Exigimos que a Adidas ponha fim à comercialização desses produtos. Lembramos que no Brasil há leis duras para reprimir abusos sexuais e as polícias irão atuar nesses casos no território nacional. 0 povo brasileiro é acolhedor e tenho certeza de que aqueles que nos visitarão irão respeitar o Brasil. (PIERRY, EBOLI, 2014).

A fala do representante da Embratur informa ao leitor que alguém do governo tomará medidas cabíveis para exigir respeito e restabelecer a ordem. Um reforço a essa primeira manifestação foi a fala da secretária de enfrentamentos à violência da Secretaria de Política Para as Mulheres, Aparecida Gonçalves: 
Achei uma campanha (daAdidas) complicada. Para não dizer outra coisa. 0 legado que 0 Brasil tem para as mulheres não é esse. Estamos num país em que, efetivamente, as mulheres estão tendo mais acesso e lutando por igualdade. Não vamos aceitar esse tipo de propaganda da Adidas nos Estados Unidos. É inadmissível. Avançamos quando elegemos uma presidente da República mulher, temos partidos políticos que discutem paridade entre homem e mulher no Parlamento; mulheres que estão no mercado de trabalho ocupando espaço nas empresas, que são grandes empresárias, grandes executivas. (PIERRY, EBOLI, 2014).

0 primeiro a ganhar espaço no jornal foi um homem, ligado ao campo do turismo. Em seguida, uma mulher, com status de ministra, cuja tarefa é lutar contra a violência cometida contra as mulheres. A discussão começava a subir na escala hierárquica com 0 acionamento de instâncias mais poderosas, a fim de que satisfações fossem tomadas.

No plano internacional, o jornal britânico The Guardian, em sua edição eletrônica de 26 de fevereiro de 2014, informou que Adidas to stop selling Brazil World Cup T-shirts that 'encourage sexual tourism ${ }^{6}$. 0 jornal ainda divulgou que a marca de roupas esportivas suspendeu a venda dessas camisetas da Copa do Mundo depois que a ministra de assuntos da mulher disse que as camisetas eram ofensivas. A matéria prosseguia dizendo que "os desenhos tocam os nervos no Brasil onde as pessoas frequentemente queixam- se dos estereótipos estrangeiros da sensualidade brasileira"7 0 jornal ressaltou a fala do presidente da Embratur. Na sequência, o jornal britânico colocou em destaque a voz da presidente do Brasil, Dilma Rousseff, afirmando que "o país vai coibir o turismo sexual e a exploração de crianças durante a competição". Ainda segundo o jornal, Rousseff disse que "0 Brasil está feliz com a vinda de turistas para a Copa do Mundo, mas também preparado para combater o turismo sexual". Finalmente, The Guardian acentua 0 discurso da ministra dos assuntos da mulher que diz: "As camisetas não são somente ofensivas às mulheres brasileiras, mas expõem todas ao barbarismo dos predadores sexuais. Tudo isso é mais chocante em um país que elegeu legitimamente uma mulher como a sua mais alta autoridade e que manifesta um grande respeito pela mulher e zero de tolerância a qualquer forma de violência contra ela".

Outro veículo estrangeiro a dar cobertura às camisetas foi a rádio francesa FranceInfo. Com a chamada "Brasil: Adidas acusada de incitar 0 turismo sexual", a rádio abriu o assunto. Segundo 0 site da rádio francesa, "A quatro meses da Copa do Mundo de futebol, Adidas recebe um cartão vermelho e retira do mercado americano camisetas ambíguas. 0 Brasil reprova a marca esportiva por incitar o turismo sexual. A empresa

http://www.franceinfo.fr/monde/bresil-adidas-accuse-d-inciter-au-tourisme-sexuel-1331965-2014-02-26.

http://www.theguardian.com/world/2014/feb/26/adidas-stop-selling-offensive-world-cup-t-shirts-brazil. 
alemã não escolheu os bons slogans nem as boas fotos para vangloriar o Brasil9". A matéria da rádio colocava em evidência a reação das autoridades: "A raiva de uma ministra e a reação da presidente conduziram o grupo alemão a anunciar nesta terça-feira a retirada das prateleiras de uma coleção julgada desrespeitosa em relação ao Brasil ${ }^{10 ”}$. Com o título de "A cúpula do Estado em alerta", a rádio FranceInfo sublinha a reação da mídia brasileira: "Vários jornais no Brasil falaram do caso das camisetas sugestivas. Imediatamente as redes sociais fizeram circular as fotos que provocaram a ira da ministra da política para as mulheres. Elonora Menicucci falou de falta de respeito, de agressão e de turismo sexual. Essa campanha comercial estimula a predação sexual, as imagens e as frases ligam o Brasil ao turismo sexual”. A rádio francesa prossegue dando ênfase ao discurso da presidente: "Do seu lado, a presidente Dilma Rousseff reagiu em sua conta do Twitter postando uma mensagem indireta sem citar a Adidas. Dilma Rousseff anuncia um reforço da luta contra a exploração sexual de crianças e adolescentes durante a Copa do Mund $0^{11 "}$. A matéria termina com a imagem da conta do Twitter da presidente exibindo a mesma frase citada pelo The Guardian sobre o país estar feliz em receber turistas para a Copa, mas também estar pronto para combater o turismo sexual ${ }^{12}$.

\section{Turismo sexual e imaginário: problema social ou problema sociológico?}

Afinal, seriam as representações estampadas nas camisetas da Adidas incitadoras do turismo sexual? Estaria a mulher brasileira sendo agredida, humilhada e explorada pela empresa alemã? Não passaria tudo de um grande mal-entendido?

As questões citadas anteriormente levam a observar que uma das imagens presentes nas duas camisetas se impõe: trata-se de nádegas. Parte privilegiada do corpo feminino na cultura brasileira e latina, 0 derrière, talvez melhor que qualquer outra parte do corpo, exprime aspectos importantes do imaginário nacional. 0 coração que veste um biquíni junto à frase "I Love Brazil" parece apontar para uma imagem estruturada pela energia dominante copulativa. Ao mesmo tempo, ela remete ao domínio do orgiástico e do deus grego Dionísio, um dos casos de figura abordados por Maffesoli: "À imagem de Dionysos, o deus de vários rostos, 0 orgiástico social é ele mesmo plural" (1985, p.14).

Maffesoli nota que os valores dominantes dos últimos quatro séculos centrados no papel do indivíduo moderno, senhor de si mesmo, autônomo e racional são implodidos pela nova socialidade orgiástica. Assim, ganham destaque

http://www.franceinfo.fr/monde/bresil-adidas-accuse-d-inciter-au-tourisme-sexuel-1331965-2014-02-26.

http://www.franceinfo.fr/monde/bresil-adidas-accuse-d-inciter-au-tourisme-sexuel-1331965-2014-02-26.

11 http://www.franceinfo.fr/monde/bresil-adidas-accuse-d-inciter-au-tourisme-sexuel-1331965-2014-02-26.

12 http://www.franceinfo.fr/monde/bresil-adidas-accuse-d-inciter-au-tourisme-sexuel-1331965-2014-02-26. 
representações presentes nas camisetas que se aproximam de outras ressaltadas pelo sociólogo francês: "ser senhor de si mesmo como do Universo não tem mais grande sentido, outras qualidades como a moleza, a passividade, a perda em seu sentido mais geral, merecerão atenção" (1985, p.17).

Desse modo entendendo, é relevante lembrar que, do ponto de vista estrito da análise sociológica ou antropológica, os produtos da marca alemã são indiferentes, afinal, estamos em um universo onde os atores sociais posicionam-se em função de seus valores e de seus interesses. Isso pode chocar um leitor ávido por medidas que coíbam o turismo sexual. Mas é importante em termos metodológicos de apresentar. A questão para 0 analista é sobre as interações que se estabelecem em torno do problema social.

Podemos, é claro, nos posicionar contra ou a favor das mensagens, desde que estejamos cientes de que 0 fazemos como quaisquer membros da sociedade e não como cientistas sociais. Nesse caso, a questão não é, finalmente, ser contra ou a favor, mas deixar claro de que lado se está (BECKER, 1978). Talvez, assim, comece a ficar claro que, para o cientista social e para 0 cidadão, a definição de problema social e sociológico não é a mesma.

Muito do que está em jogo na polêmica das camisetas deve-se à forma como a questão é obscurecida quando vista somente em termos de um problema social. Mas, o que é um problema social e de que maneira ele impede que vejamos além das fachadas oficiais?

Tomando o texto "A sociologia como forma de consciência", de Peter Berger (1980), estamos, para todos os efeitos, diante de uma situação em que temos pelo menos dois tipos de problemas em jogo. 0 primeiro deles diz respeito a isso que chamamos de problema social e que envolve o que um grupo social considera como sendo um erro, uma falta ou ainda quando alguma coisa não funciona corretamente na sociedade nos moldes prescritos pelas definições oficiais. 0 posicionamento do governo brasileiro representa bem a noção de problema social: as imagens das camisetas ofendem o que o governo crê ser 0 correto.

De acordo com Berger (1980), o analista social, seja ele sociólogo, antropólogo ou jornalista, é convocado pelos agentes sociais a estudar 0 problema segundo a sua definição oficial. Em grande parte, também se espera do cientista social que identifique e solucione o problema social, uma vez que sua ocorrência oferece um grave risco à ordem social. Berger argumenta ainda que o problema sociológico difere radicalmente do problema social e parte, então, para sua explicação. Conforme 0 autor, seríamos ingênuos ao acreditar que 0 crime, bem como 0 divórcio são problemas simplesmente porque a organização policial ou os moralistas assim o definiram. Ainda 
segundo Berger (1980), o que é um problema para policiais, assistentes sociais, moralistas, políticos ou religiosos não necessariamente tem de ser um problema para o sociólogo.

Radicalmente diferente do problema social, o problema sociológico envolve sempre a compreensão do que ocorre em termos de interação social (BERGER,1980). Em outras palavras, ao invés de adotar a definição oficial do que um grupo, instituição ou organização social e sua hierarquia de credibilidade (BECKER, 1978) consideram como um mau funcionamento da sociedade ou de parte de seus membros - algo que podemos chamar de comportamento desviante -, o sociólogo busca compreender as diferentes perspectivas ou pontos de vista implicados na relação. É por isso que Berger mostra que a compreensão da interação social consiste em conhecer como funciona o sistema social, seus pressupostos, assim como a maneira pela qual sua coesão é assegurada (BERGER, 1980, p.47).

Ao ocupar-se de problemas sociológicos como interação social, a atividade sociológica é, desse modo, eminentemente desmitificadora, afirma Berger (1980). Ele quer dizer, com isso, que a atividade sociológica consiste menos em colocar-se a favor ou do lado de uma perspectiva ou ordem de realidade social oficial do que buscar ver o sistema social como um todo, e isso significa buscar por ordens ou interpretações sociais antagônicas. Nesse sentido, a atividade sociológica é desmitificadora principalmente do ponto de vista metodológico. Dito de outro modo, as interpretações oficiais da sociedade tendem a ocultar ou obscurecer o fato de que as realidades sociais são sempre 0 efeito de ações recíprocas. É justamente nesse ponto que entra 0 imaginário: as interpretações oficiais, assim como os problemas sociais são calcados no imaginário de uma época, em uma simbólica, sem que os agentes tenham necessariamente consciência disso.

\section{Considerações finais}

0 imaginário é um processo que ganha forma tendo no corpo, inserido no interior de uma cultura, um elemento de grande importância; constitui-se em uma bacia semântica e percorre um trajeto antropológico (Durand, 2003) que assinala as idas e vindas do simbólico. Dessa maneira, o imaginário é estruturado no inconsciente, mas é profundamente dependente do que se passa no mundo da cultura com seus dramas, dúvidas e impasses.

A publicidade, como assinalam Detrez (2002) e Wunenburger (2013), certamente assume um papel mais do que central na dinamização dos imaginários contemporâneos, ainda que, por vezes, ao custo de uma nova forma de dominação. Se antes a atualização dos imaginários coletivos era reservada a importantes atores e instituições sociais, como feiticeiros, xamãs, bruxas, mitos e lendas, contemporaneamente a publicidade e 0 turismo também assumem esse papel. 
Assim, a veiculação de representações do corpo feminino brasileiro de biquíni por uma empresa multinacional mobilizou um vasto conjunto de atores sociais, cujos discursos reiteraram a luta contra a exploração da mulher no Brasil. As imagens estampadas em duas camisetas da marca, parte da estratégia de promoção de seus produtos durante um megaevento esportivo, não passaram despercebidas. 0 caráter ambíguo imagens jamais veiculam um sentido fechado - armou uma arena onde sujeitos ancorados em determinadas posições foram chamados a se posicionar frente a um problema, o que funcionou como um poderoso catalisador do imaginário implícito nas representações. Por um lado, tais imagens remetem ao universo da sensualidade e do prazer; por outro, remetem à submissão e à passividade, tratam a mulher como objeto dócil, expõem traumas e cicatrizes de uma sociedade repleta de contradições.

Essa situação confronta 0 analista social diante do problema: social ou sociológico? As imagens das nádegas e do corpo feminino são um problema para quem? Certamente, um problema social para empresários morais ou o governo, para os quais constituem uma ofensa. Nesse contexto, o papel do analista social não é o de aderir nem o de engrossar as fileiras daqueles cujos valores e pontos de vista engendram mais um olhar sobre a realidade. Sua tarefa, para retomar algumas ideias caras a Berger e Becker, é compreender o que se passa em termos de interação social. Daí a questão configurar-se também como um problema de ordem sociológica.
A situação estudada mostra um objeto imagético ambíguo, simbólico, do qual o sentido jamais é totalmente claro. Nessa perspectiva, as imagens nas camisetas possuem inúmeras faces, podem atentar contra a mulher brasileira ou não. Dessa maneira, ainda que o sentido simbólico veiculado pela imagem não seja inequívoco, ele é portador de conteúdo. Enfim, as representações do corpo feminino integram um vasto acervo de mitos, de narrativas de viagens e de publicidade - um museu de imagens. Por isso, não se trata simplesmente de julgar imagens como ofensivas à mulher brasileira, porém tentar olhar um mito que se atualiza a partir da forma como histórica, política e mesmo economicamente se situam os sujeitos sociais, mesmo que, ao identificar um problema sociológico, reconheçamos um problema social e não possamos deixar de mencionar as implicações de tais imagens.

\section{Referências}

BECKER, Howard S. De que lado estamos? In: Uma teoria da ação coletiva. Rio de Janeiro: Zahar, 1978. p.122-137.

BERGER, Peter L. A sociologia como forma de consciência. In: . Perspectivas sociológicas : uma visão humanística. 5.ed. Petrópolis: Vozes, 1980. p.35-64. B0Z0N, Michel. Sociologie de la sexualité. Paris: Armand Colin, 2005.

DETREZ, Christine. La construction sociale du corps. Paris: Éditions du Seuil, 2002.

DURAND, Gilbert. Limagination symbolique. 5.ed. Paris : PUF, 2003. 
Introduction à la mythodologie: mythes et sociétés. Paris: Albin Michel, 1996.

LE BRETON, David. Anthropologie du corps et modernité. Paris: PUF, 2005.

LÉVI-STRAUSS, Claude. 0 pensamento selvagem. Campinas: Papirus, 1991.

MAFFESOLI, Michel. Lombre de Dionysos: contribution à une sociologie de l'orgie. Paris: Méridiens, 1985.

MAUSS, M. Les techniques corporelles. In: Sociologie et anthropologie. 9. ed. Paris: PUF, 1985. p. 365-388.

MICHEL, Frank. Voyages pluriels: échanges et mélanges. Annecy: Livres du monde, 2011.

SIQUEIRA, Denise da Costa 0. (org). A construção social das emoções: corpo e produção de sentidos na comunicação. Porto Alegre: Sulina, 2015.

SIQUEIRA, Euler David de, SIQUEIRA, Denise da Costa Oliveira. 0 corpo como imaginário da cidade. Revista Famecos, Porto Alegre, v. 18, n. 3, dez/2011, p. 657-673. Corpos autorizados: comunicação, poder e turismo. Conexão (Caxias do Sul). , v.6, p.81 - 98, 2007. WUNENBURGER, Jean-Jacques. 0 arquipélago imaginário do corpo virtual. Alea, v. 8, n. 2, jul.dez. 2006, p. 193-204.

. L'imaginaire. 2.ed. Paris: PUF, 2013.

URBAIN, Jean Didier. Sur la plage: mœurs et coutumes balnéaires. Paris : Payot, 1994.

\section{Filmografia}

MURAT, Lucia. Olhar estrangeiro. Documentário. 2006.

\section{Material jornalístico}

GLOBO ESPORTE. Após polêmica, Adidas retira das lojas linha da Copa com conotação sexual. Camisas criaram mal-estar com brasileiros. Embratur vê analogia ao turismo sexual. GloboEsporte.com. 25/02/2014. Disponível em: http://globoesporte.globo. com/futebol/copa-do-mundo/noticia/2014/02/apospolemica-adidas-retira-das-lojas-camisas-da-copa-comconotacao-sexual.html . Consulta em 08/02/2016.

FRANCE INFO. Adidas accusé d'inciter au tourisme sexuel. France Info. 26/02/2014. http://www.

franceinfo.fr/monde/bresil-adidas-accuse-d-inciterau-tourisme-sexuel-1331965-2014-02-26 . Consulta em 08/02/2016.

PIERRY, Flávia, ÉBOLI, Evandro. Camiseta vendida nos EUA usa apelo sexual vinculado à Copa no Brasil. 0 Globo.com. 24/02/2014. Disponível em: http:// oglobo.globo.com/esportes/camiseta-vendida-nos-euausa-apelo-sexual-vinculado-copa-no-brasil-11696324 . Acesso em 08/02/2016.

THE GUARDIAN. Adidas to stop selling Brazil World Cup T-shirts that 'encourage sexual tourism'. The Guardian. 26/02/2014. http://www.theguardian.com/ world/2014/feb/26/adidas-stop-selling-offensive-worldcup-t-shirts-brazil . Acesso em 03/03/2014. 


\section{The seductives of the t-shirt: myth, conflict and imaginary at stake}

\section{Abstract}

The aim of this paper is to investigate the production of meanings about the female body from a gender imaginary highlighted by the media. Starting from a theoretical framework that includes Durand, Wunenberger and Le Breton, we make a reading of the polemic triggered by the release of products related to the World Cup containing ambiguous images of the Brazilian women. The polemic issue was highlighted in the international press by introducing a polyphonic and polysemic field full of tension. Methodologically, this is a quality-oriented nature research founded in the principles of the comprehensive sociology. Through documentary research of media material, as well as a reading of the discourses, we relate myths, imaginary and conflicts given their opposition and complementarity. Finally, making use of the distinction between social problem and sociological problem, we try to understand the situation in terms of social interaction.

\section{Keywords}

Body. Imaginary. Gender. Conflict. Interaction.

\section{Las sedutoras de la camiseta: mito, conflicto e imaginario en juego}

\section{Resumen}

El propósito de este artículo es investigar la producción de sentidos sobre el cuerpo de la mujer desde um imaginario de género puesto en evidencia por los medios de comunicación. A partir de un marco teórico que incluye Durand, Wunenburger y Le Breton, hacemos una lectura de la polémica desencadenada por la liberación de productos para la Copa del Mundo celebrada en Brasil que contenían imágenes ambiguas sobre la mujer brasileña. La cuestión se puso de relieve en la prensa internacional mediante la introducción de un campo polifónico y polisémico lleno de tensión. Metodologicamente, se trata de una investigación cualitativa guiada por principios de la sociología comprensiva. A través de la investigación documental de material de los medios de comunicación, así como la lectura de los discursos, relacionamos mitos, imaginarios y conflictos, considerando su oposición y complementariedad. Por último, haciendo uso de la distinción entre problema social y problema sociológico, tratamos de entender la situación en términos de interacción social.

\section{Palabras clave}

Cuerpo. Imaginario. Género. Conflicto. Interacción. 


\section{Expediente}

A revista E-Compós é a publicação científica em formato eletrônico da Associação Nacional dos Programas de Pós-Graduação em Comunicação (Compós). Lançada em 2004, tem como principal finalidade difundir a produção acadêmica de pesquisadores da área de Comunicação, inseridos em instituições do Brasil e do exterior.

\section{E-COMPÓS I www.e-compos.org.br I E-ISSN 1808-2599}

Revista da Associação Nacional dos Programas de Pós-Graduação em Comunicação.

Brasília, v.19, n.3, set./dez. 2016.

A identificação das edições, a partir de 2008, passa a ser volume anual com três números.

Indexada por Latindex I www.latindex.unam.mx

\section{CONSELHO EDITORIAL}

Alexandre Farbiarz, Universidade Federal Fluminense, Brasil Alexandre Rocha da Silva, Universidade Federal do Rio Grande do Sul, Brasil Ana Carolina Escosteguy, Pontifícia Universidade Católica do Rio Grande do Sul, Brasil Ana Carolina Rocha Pessôa Temer, Universidade Federal de Goiás, Brasil Ana Regina Barros Rego Leal, Universidade Federal do Piauí, Brasil Andrea França, Pontifícia Universidade Católica do Rio de Janeiro, Brasil André Luiz Martins Lemos, Universidade Federal da Bahia, Brasil Antonio Carlos Hohlfeldt, Pontifícia Universidade Católica do Rio Grande do Sul, Brasil Arthur Ituassu, Pontifícia Universidade Católica do Rio de Janeiro, Brasil Álvaro Larangeira, Universidade Tuiuti do Paraná, Brasil Ângela Freire Prysthon, Universidade Federal de Pernambuco, Brasil César Geraldo Guimarães, Universidade Federal de Minas Gerais, Brasil Cláudio Novaes Pinto Coelho, Faculdade Cásper Líbero, Brasil Daisi Irmgard Vogel, Universidade Federal de Santa Catarina, Brasil Denize Correa Araujo, Universidade Tuiuti do Paraná, Brasil

Eduardo Antonio de Jesus, Pontifícia Universidade Católica de Minas Gerais, Brasil Daniela Zanetti, Universidade Federal do Espirito Santo, Brasil

Eduardo Vicente, Universidade de São Paulo, Brasil

Elizabeth Moraes Gonçalves, Universidade Metodista de São Paulo, Brasil Erick Felinto de Oliveira, Universidade do Estado do Rio de Janeiro, Brasil Francisco Elinaldo Teixeira, Universidade Estadual de Campinas, Brasil Francisco Paulo Jamil Almeida Marques, Universidade Federal do Paraná, Brasil Gabriela Reinaldo, Universidade Federal do Ceará, Brasil

Goiamérico Felício Carneiro Santos, Universidade Federal de Goiás, Brasil Gustavo Daudt Fischer, Universidade do Vale do Rio dos Sinos, Brasil Herom Vargas, Universidade Municipal de São Caetano do Sul, Brasil Itania Maria Mota Gomes, Universidade Federal da Bahia, Brasil Janice Caiafa, Universidade Federal do Rio de Janeiro, Brasil Jiani Adriana Bonin, Universidade do Vale do Rio dos Sinos, Brasil
José Afonso da Silva Junior, Universidade Federal de Pernambuco, Brasil José Luiz Aidar Prado, Pontifícia Universidade Católica de São Paulo, Brasil Juçara Gorski Brittes, Universidade Federal de Ouro Preto, Brasil Kati Caetano, Universidade Tuiuti do Paraná, Brasil Lilian Cristina Monteiro França, Universidade Federal de Sergipe, Brasil Liziane Soares Guazina, Universidade de Brasilia, Brasil Luíza Mônica Assis da Silva, Universidade de Caxias do Sul, Brasil Luciana Miranda Costa, Universidade Federal do Pará, Brasil Malena Segura Contrera, Universidade Paulista, Brasil Monica Martinez, Universidade de Sorocaba, Brasi Maria Ataide Malcher, Universidade Federal do Pará, Brasil Marcia Tondato, Escola Superior de Propaganda e Marketing, Brasil Marcel Vieira Barreto Silva, Universidade Federal da Paraíba, Brasil Maria Clotilde Perez Rodrigues, Universidade de São Paulo, Brasil Maria das Graças Pinto Coelho, Universidade Federal do Rio Grande do Norte, Brasil Mauricio Ribeiro da Silva, Universidade Paulista, Brasil

Mauro de Souza Ventura, Universidade Estadual Paulista, Brasil Márcio Souza Gonçalves, Universidade do Estado do Rio de Janeiro, Brasil Micael Maiolino Herschmann, Universidade Federal do Rio de Janeiro, Brasil Mirna Feitoza Pereira, Universidade Federal do Amazonas, Brasil Nísia Martins Rosario, Universidade Federal do Rio Grande do Sul, Brasil Potiguara Mendes Silveira Jr, Universidade Federal de Juiz de Fora, Brasil Regiane Regina Ribeiro, Universidade Federal do Paraná, Brasil Rogério Ferraraz, Universidade Anhembi Morumbi, Brasil Rose Melo Rocha, Escola Superior de Propaganda e Marketing, Brasil Rozinaldo Antonio Miani, Universidade Estadual de Londrina, Brasil Sérgio Luiz Gadini, Universidade Estadual de Ponta Grossa, Brasil Simone Maria Andrade Pereira de Sá, Universidade Federal Fluminense, Brasil Veneza Mayora Ronsini, Universidade Federal de Santa Maria, Brasil Walmir Albuquerque Barbosa, Universidade Federal do Amazonas, Brasil

\section{CONSELHO CIENTÍFICO}

Cristiane Freitas Guttreind, Pontifícia Universidade Católica do Rio Grande do Sul, Brasil Eduardo Morettin, Universidade de São Paulo, Brasil Felipe Costa Trotta, Universidade Federal Fluminense, Brasil Irene de Araújo Machado, Universidade de São Paulo, Brasil

\section{COMISSÃO EDITORIAL}

Eduardo Antonio de Jesus, Pontifícia Universidade Católica de Minas Gerais, Brasil Osmar Gonçalves dos Reis Filho, Universidade Federal do Ceará, Brasil

\section{CONSULTORES AD HOC}

Geane C. Alzamora, Universidade Federal de Minas Gerais, Brasil Teresinha Cruz Pires, Pontifícia Universidade Católica de Minas Gerais, Brasil

\section{EQUIPE TÉCNICA}

ASSISTENTE EDITORIAL Márcio Zanetti Negrini

REVISÃO DE TEXTOS Press Revisão

EDITORAÇÃO ELETRÔNICA Roka Estúdio

IMAGEM DE CAPA Silas de Paula

\section{COMPÓS I www.compos.org.br}

Associação Nacional dos Programas de Pós-Graduação em Comunicação

Presidente

Edson Fernando Dalmonte

Programa de Pós-Graduação em Comunicação

e Cultura Contemporânea - UFBA

edsondalmonte@uol.com.br

Vice-presidente

Cristiane Freitas Gutfreind

Programa de Pós-Graduação em Comunicação Social - PUC-RS cristianefreitas@pucrs.br

Secretário-Geral

Rogério Ferraraz

Programa de Pós-Graduação em Comunicação

Universidade Anhembi Morumbi

rogerioferraraz@anhembimorumbi.edu.br

CONTATO I revistaecompos@gmail.com 